\title{
Development of Nanoprobe for the Determination of Blood Cholesterol
}

Jeyashanthi-Navamani*, Ravikumar-Palanisamy, Gurusamy R, Murugasami-Ramasamy and Arumugam $\mathrm{S}$

Velalar college of Engineering and Technology, Erode, Tamilnadu, India

\begin{abstract}
Measurements of serum cholesterol levels are important in the diagnosis and classification of hyper lipoproteinemias. Elevated cholesterol levels may occur with hypothyroidism, nephrotic syndrome, diabetes, and various liver diseases. The present investigation was carried out for the development of rapid, highly sensitive and economic cholesterol biosensor for the determination of blood cholesterol. The PVP encapsulated ZnS nanoparticals have been synthesized and characterized by Fourier Transform InfraRed (FTIR) spectroscopy, UV-visible spectroscopy, and Atomic force microscopy techniques in the present investigation. The size of the nanoparticles is found to be ranging between 21-22 $\mathrm{nm}$.

The surface morphology of the sensing area of functionalized MWCNT was examined using Scanning Electron Microscopy (SEM). The length of the MWCNTs is found to be approximately 2 microns. In the IR spectrum of functionalized MWCNTs, the presence of bands at $1636 \mathrm{~cm}^{-1}$ and $3434 \mathrm{~cm}^{-1}$ confirmed the presence of carbonyl and hydroxyl moieties of carboxylic acid group.

Cholesterol Oxidase was immobilized on to the ZnS nanoparticles and Multiwall Carbon Nanotubes (MWCNTs) which they were placed on a glassy carbon electrode surface using Nafion by LBL assembly technique. Cyclic voltammetric study reveals that the fast electron transfer between electrodes was achieved through the incorporation of ChOx into the Nafion-ZnS-MWCNTs film. ZnS and MWCNTs played an important role in facilitating the electron transfer between the ChOx and the electrode surface.

The cholesterol bioelectrode shows detection range of $10-450 \mathrm{mg} / \mathrm{dl}$ and good linearity is obtained in $50-450$ $\mathrm{mg} / \mathrm{dl}(1.3-11.6 \mathrm{mM})$ range with linear regression coefficient 'R2' as 0.986 . The Michaelis-Menten constant $K_{m}$ value obtained as $0.84 \mathrm{mM}$ using Lineweaver-Burke plot by plotting $1 / \mathrm{V}$ vs $1 /$ Conc. The low $K_{m}$ value $0.84 \mathrm{mM}$ indicates high affinity of immobilized $\mathrm{ChOx}$ to cholesterol. It exhibits optimum $\mathrm{pH} 7.0$ and optimum temperature $35^{\circ} \mathrm{C}$. Therefore, the bioelectrode fabricated in this study is promising for cholesterol detection in human blood.
\end{abstract}

Keywords: Multi walled carbon nanotubes; Cholesterol oxidase; Nafion; Michaelis-Menten constant; Zinc sulphate nanoparticles

\section{Introduction}

The estimation of blood cholesterol concentration is one of the most widely performed assays in clinical laboratory. Accurate measurement of cholesterol level in blood has long been recognized as an important clinical test for diagnosing the cardiovascular diseases and many patients are using the disposable cholesterol strips for self monitoring their blood cholesterol levels. The limiting step for commercialization of disposable cholesterol strip is immobilization procedures of the enzyme. The basic concept of enzyme based cholesterol sensor is refer to the glucose sensor was first described by Clark and Lyon [1]. Since the pioneer work, reasonable research work has been done to the development of cholesterol sensors. The majorities of sensors are based on electrochemical principles and use enzymes as biological component for analyte recognition. The most widely used active electrode materials are Carbon [2], conducting polymers [3] and transition metal oxides [4].

A number of electrochemical cholesterol biosensor have been developed employing cholesterol esterase, Cholesterol Oxidase and peroxidase immobilized onto octyl agarose gel, pyrole membrane, nylon mesh, screen printed strip, Carbon paste electrode, polypyrrole film, graphite-teflon matrix, dialysis membrane, conducting polypyrrole films, polyanniline films and nano sized materials. It is based on the following chemical reactions [5].

Cholesterolacetate $+\mathrm{H}_{2} \mathrm{O} \stackrel{\text { Cholesterolesterase }}{\longrightarrow}$ Cholesterol + Acidicacid

Cholesterol $+\mathrm{O}_{2} \stackrel{\text { Cholesteroloxidase }}{\longrightarrow}$ Cholesten-3-one $+\mathrm{H}_{2} \mathrm{O}_{2}$

$2 \mathrm{H}_{2} \mathrm{O}_{2}+$ Phenol +4 -aminoantipyrine $\stackrel{\text { Peroxidase }}{\longrightarrow}$ Quinoeminedye $\left(\lambda_{\max }=520 \mathrm{~nm}\right)$
Conventional electrochemical biosensors are based on either glassy Carbon electrodes (GCE) or metal electrodes ( $\mathrm{Au}, \mathrm{Pt}$ or $\mathrm{Cu}$ for example) for amperometric or voltammetric analyte detection. Such electrodes have a series of disadvantages, including poor sensitivity and stability, low reproducibility, large response times, slow electron transfer reaction and a high potential for electron transfer reactions [6]. CNTs can overcome most of these disadvantages owing to their ability to undergo fast electron transfer and the resistance of CNT-modified electrodes to surface fouling.

Carbon nanotubes are among the most extensively researched materials today. This is the most versatile material, with the properties ranging from optical absorption and emission on one hand to the mechanical properties of bulk materials such as young's modulus, on the other [7]. The electrochemical reactivity of important biomolecules is enhanced by CNT, promote the electron-transfer reactions of enzymes containing redox center and enhance electrochemical reactivity, CNTmodified electrodes have been shown used for accumulating important biomolecules such as enzymes and for alleviating surface fouling effects such as in the NADH oxidation process. The sensitive CNT conductivity

${ }^{*}$ Corresponding author: Jeyashanthi-Navamani, Velalar college of Engineering and Technology, Erode, Tamilnadu, India, E-mail: njeyashanthi@gmail.com

Received June 02, 2012; Accepted June 20, 2012; Published June 25, 2012

Citation: Navamani J, Palanisamy R, Gurusamy R, Ramasamy M, Arumugam S (2012) Development of Nanoprobe for the Determination of Blood Cholesterol. J Biosens Bioelectron 3:122. doi:10.4172/2155-6210.1000122

Copyright: () 2012 Navamani J, et al. This is an open-access article distributed under the terms of the Creative Commons Attribution License, which permits unrestricted use, distribution, and reproduction in any medium, provided the original author and source are credited. 
to the surface adsorbates permits the use of CNT as nanoscale sensors. CNTs are used in wide range of electrochemical biosensors ranging from amperometric enzyme electrodes to DNA chip.

Multiwall Carbon Nanotubes (MWCNTs) can be used as suitable intermediates between electrodes and enzymes, because of their high surface area, high surface to volume ratio, good electrical conductivity and significant mechanical strength [8]. MWCNT enhance electrocatalytic activity due to presence of edge-plane-like sites located at both ends and in the defect region [9]. Besides this, MWCNT produce changes in energy bands close to Fermi level [10]. MWCNT have recently been utilized for fabrication of electrochemical biosensor [11].

The nanostructured metal particles have profound applications in optics, optoelectronics, sensors, and actuators due to their semiconducting, piezoelectric, and pyroelectric properties [12]. Among these semiconductor nanocrystals or quantum dots have gained considerable interest during the past decade. These materials have unique technological applications for various photoelectronic devices or even for advanced biotechnology due to their size dependant physical and optical properties [13]. Nanomaterials prepared from metals, shaped into Nano particles have been widely used for their ability as electrode modification materials to enhance the efficiencies of electrochemical biosensors [14]. Metal nano particles can increase efficiency of photochemical reactions and greatly improve the catalytic activity of enzymes to generate novel photo electrochemical systems.

Metal nano particles possess high surface area, chemical stability and shows fast electron communication features [15]. The high electron communication features, high surface to volume ratio and electro-catalytic activity of the nanosized materials make them ideal as immobilization matrices, as transduction platform and/or mediators. To improve the stability, sensitivity, selectivity and other analytical characteristics of biosensors various conventional materials matrices have been used. Among them metal nanoparticles retain the bioactivity of the immobilized enzyme and enhance the sensing characteristics such as sensitivity, selectivity and low detection limit of the biosensors.

Among the several metal nano materials that have been tested for biosensing applications, ZnS represents an excellent material with a high isoelectric point that allows easy immobilization of an enzyme (with a low isoelectric point) through electrostatic interaction [16]. Furthermore, its high chemical stability and non-toxic nature, as well as its biocompatibility and high electron transfer capability make $\mathrm{ZnS}$ a promising material for building an enzymatic sensor by immobilizing the appropriate biomolecules without electron mediators. Such type of ZnS-based biosensors can also be used to further develop implantable biosensing systems.

Conducting electroactive polymers (CPs) have aroused considerable interest due to their electronic conducting properties and unique chemical and biochemical properties. Conducting polymers are multifunctional materials that can be employed as receptors as well as transducers or immobilization matrices in electrochemical biosensing. They are characterized by an extended $\pi$ - conjugation along the polymer backbone, which promotes an intrinsic conductivity, ranging between $1 \mathrm{E}-14$ and $1 \mathrm{E} 2 \mathrm{~S} / \mathrm{cm}$ [17]. Their electrical conductivity results from the formation of charge carriers ("doping") upon oxidizing (p - doping) or reducing ( $\mathrm{n}$ - doping) their conjugated backbone [18]. They have the characteristics of organic polymers, such as light weight, resistance to corrosion, flexibility, and ease of fabrication [19]. When formed as nanostructures, conductive polymers acquire appealing properties: ease of preparation by chemical or electrochemical methods, sensitivity towards a wide range of analytes, considerable signal amplification due to their electrical conductivity, and fast electron transfer rate [20].

CPs are easily synthesized and deposited onto the conductive surfaces by electrochemical polymerization. Coating electrodes with CPs open up numerous possibilities for the immobilization of biomolecules on the electrode surface. They improve the bioaffinity, electrocatalytic properties, electron transfer rate and direct communication to produce analytical signals. Co-immobilization of other molecules (enzymatic co-factors or charge-transfer mediators) by entrapment within $\mathrm{CP}$ films or by covalent binding on these films permits straight forward fabrication of reagentless biosensors [21].

Nafion, a sulfonated tetrafluorethylene copolymer, consists of a hydrophobic fluoroCarbon backbone (-CF2-CF2-) to which hydrophilic sulfonate groups (SO3-) are attached (Mauritz and Moore, 2004). The presence of negatively charged sulfonate groups in the membrane explains the high level of proton conductivity of Nafion. That has attracted much interest owing to its interesting properties such as biocompatibility, non-toxicity, low-cost, good film forming ability, high mechanical strength, high hydrophilicity, chemical and electrochemical stability, extremely low permeability to reactant species, selective and high ionic conductivity, and ability to provide electronic insulation [22].

In the present work, a novel nanoprobe for blood cholesterol determination has been constructed by LBL Self assembly technique. GC electrode was modified with ZnS, Nafion and excellent conductive MWCNTs. Cholesterol Oxidase simply entrapped into the $\mathrm{ZnS} /$ MWCNTs composite and Nafion was used as to give stable and homogeneous cast thin films. Meanwhile, this new electrochemical system can utilize synergy effect between MWCNTs and ZnS to facilitate electron-transfer processes and retain the good bioactivity of Cholesterol Oxidase. This biosensing probe based on ZnS/MWCNTs/ Nafion/ChOx/GC electrode responded sensitively to cholesterol.

\section{Experimental Procedure}

\section{Reagents}

Cholesterol Oxidase (ChOx) from Nocardia sp, (E.C. 1.1.3.6), Nafion (5 wt\% in lower aliphatic alcohols) and cholesterol were purchased from Sigma. Aldrich. $10 \mathrm{mg} \mathrm{ml}^{-1} \mathrm{ChOx}$ solution was obtained by dissolving ChOx in 0.05M PBS ( $\mathrm{pH}$ 6.0) and stored at $4^{\circ} \mathrm{C}$ in a refrigerator. Different concentrations of cholesterol stock standard solutions were prepared in $0.05 \mathrm{M}$ PBS ( $\mathrm{pH}$ 6.0). Cadmium nitrate ( $\geq 99.0 \%$ ), sodium sulfide $(\geq 99.0 \%)$, soluble starch, zinc acetate tetrahydrate (G.R, Glaxo laboratories India Ltd.), thiourea (G.R., S.D.Fine Chem.Ltd.), poly-N-vinyl-2-pyrrolidone (PVP, molecular weight 58,000, ACROS, USA) and N,N-dimethyl formamide (DMF, G.R., Merck, India). All other reagents were of analytical grade.

\section{Preparation of cholesterol solution}

Cholesterol solution was prepared by dissolving $400 \mathrm{mg}$ of standard cholesterol followed by addition of nonaethylene glycol monododecyl by stirring till the solution was clear and colorless at $65^{\circ} \mathrm{C}$. The hot phosphate buffer saline (PBS) pH 7.0 was added and volume made up to $100 \mathrm{ml}$. The solution was allowed to reach its normal temperature before being used and was stored at $4^{\circ} \mathrm{C}$.

\section{Apparatus}

All electrochemical experiments were carried out on a cyclic voltameter $\mathrm{CHI}$ 660C (CHI Instruments Inc., Austin, USA). A 
conventional three electrode system was used in this work. The asprepared electrode was used as the working electrode ( $1 \mathrm{~mm}$ diameter). A platinum wire was used as the counter electrode and an $\mathrm{Ag} /$ $\mathrm{AgCl}$ (saturated $\mathrm{KCl}$ ) electrode was used as the reference electrode. Phosphate Buffer System (PBS) 0.05 M (pH 6.0) was always employed as supporting electrolyte.

\section{Synthesis of PVP-encapsulated $\mathrm{ZnS}$ nanoparticles}

The synthesis reaction was carried in the N,N-Dimethyl formamide (DMF) medium. Calculated quantity of zinc acetate, thiourea and PVP was dissolved in DMF under stirring of $150 \mathrm{rpm}$ in a tightly closed glass container so as to obtain homogeneous solutions. The concentration of $\mathrm{Zn}^{2+}, \mathrm{S}^{2-}$ and PVP used in the DMF were $7.5 \times 10^{-2} \mathrm{M}, 15 \times 10^{-2} \mathrm{M}$ and $5 \times 10^{-4} \mathrm{M}$, respectively. The container with the reaction solution was thereafter placed in an oil bath, preheated at a temperature of $136 \pm$ $1^{\circ} \mathrm{C}$, for $10 \mathrm{~min}$ under constant stirring, removed from the bath and cooled to ambient temperature. The $\mathrm{pH}$ of the transparent solution was about 6 . The dispersed sulphide nanoparticles were collected from the DMF solution by adding a known volume of acetone (G.R., Merck, India). Immediate flocculation of nanoparticles occurred. Particles were collected using centrifugation at $6000 \mathrm{rpm}$. To remove the last traces of adhered impurities, the particles were washed thrice using acetone, each time collecting the particles using centrifugation as described above. The washed particles were dried at $60^{\circ} \mathrm{C}$ in air. For the measurement of the UV-Vis absorbance spectra, the dried particles were dispersed in high conductivity water (conductivity of water: $1.4 \times$ $\left.10^{-5} \mathrm{mho} / \mathrm{cm}\right)[23]$.

\section{Functionalization of MWCNT [24]}

The MWCNTs were pre-cleaned in concentrated $\mathrm{HCl}$ by sonication for 30 mins followed by continuous stirring. The reaction mixture was centrifuged, filtered and rinsed thoroughly with distilled water. Then the black solid was heated at $225^{\circ} \mathrm{C}$ for $20 \mathrm{~h}$. This was continued at $300^{\circ} \mathrm{C}$ for $1 \mathrm{~h}$ followed by sonication in $\mathrm{HCl}$. The pre-cleaning performed by concentrated $\mathrm{HCl}$ is to purify the MWCNTs especially to eliminate the residual metal catalyst particles from the nanotubes. The pre-cleaned MWCNTs were then oxidized in hot concentrated $\mathrm{HNO}_{3}$ solution for $48 \mathrm{~h}$ under refluxing conditions to remove impurities and generate surface functional groups. Purification of MWCNT surfaces prevents self-poisoning by foreign impurities while functional group generation enhances the electro catalyst formation.

\section{Preparation of the chemically modified Nafion-MWCNTS- ZnS ChOx electrodes [25]}

The procedure for the preparation of Nafion-MWCNTs-ZnS-ChOx modified electrodes was as follows: GC (Glassy Carbon) electrode with the diameter of $3 \mathrm{~mm}$ was polished with 1.0 and $0.05 \mu \mathrm{m}$ alumina slurry sequentially and then sonicated in distilled water, ethanol and distilled water for a few minutes, respectively. $0.1 \mathrm{mg}$ MWCNTs were added into $1 \mathrm{~mL}$ of $0.5 \mathrm{wt} \%$ Nafion solution, and this solution was ultrasonicated for several minutes to form a stable black suspension $(1 \mathrm{mg} / \mathrm{mL})$. Then a homogeneous solution (solution A), which finally contained $2 \mathrm{mg} / \mathrm{mL}$ ChOx, $0.5 \mathrm{ml} \mathrm{ZnS}$ and $0.1 \mathrm{mg} / \mathrm{mL}$ MWCNTs, was formed by thoroughly mixing the MWCNTs-Nafion suspension with ChOx solution $(10 \mathrm{mg} / \mathrm{ml})$ and $\mathrm{ZnS}$ solution. Four microliters of the solution A was cast onto the surface of a GC electrode by using a $10 \mu \mathrm{L}$ pipette to obtain Nafion-MWCNTs-ZnS- ChOx film modified electrode. A beaker was covered over the electrode so that water can evaporate slowly in air and a uniform film can be formed. This enzyme modified electrode was stored at $4^{\circ} \mathrm{C}$ in refrigerator when not in use.
For comparison, Nafion-ChOx/GC, Nafion-ZnS/GC, Nafion$\mathrm{ZnS}-\mathrm{ChOx} / \mathrm{GC}$ and Nafion-MWCNTs-ChOx/GC electrodes were prepared using a similar procedure. Solution $\mathrm{B}$ containing Nafion and $2 \mathrm{mg} / \mathrm{mL} \mathrm{ChOx}$ was used to prepare the Nafion-ChOx/GC electrode and solution $\mathrm{C}$ containing Nafion and $\mathrm{ZnS}$ was used to prepare the Nafion-ZnS/GC electrode. Similarly, solution D containing Nafion, 2 $\mathrm{mg} / \mathrm{mL} \mathrm{ChOx}$ and $\mathrm{ZnS}$ was used to prepare the Nafion-ZnS-ChOx/GC electrode while another solution E containing Nafion, $2 \mathrm{mg} / \mathrm{mL}$ ChOx and $0.2 \mathrm{mg} / \mathrm{mL}$ MWCNTs was used to prepare the Nafion-MWCNTs$\mathrm{ChOx} / \mathrm{GC}$ electrode. All the modified electrodes were stored at $4^{\circ} \mathrm{C}$ in refrigerator when not in use.

\section{Assay of Cholesterol Oxidase (EC 1.1.3.6)}

The reagent A $(0.5 \%(\mathrm{w} / \mathrm{v})$ Cholesterol Substrate Solution) reagent B (500 mM Sodium Acetate Buffer, pH 5.0) were pipetted out in Test and Blank Tubes. The tubes were mixed by inversion and equilibrated to $37^{\circ} \mathrm{C}$. The reagent $\mathrm{C}$ (A solution $0.005 \mathrm{unit} / \mathrm{ml}$ of Cholesterol Oxidase in Reagent $\mathrm{B}$ ) was added only to the Test tube. Immediately mixed by inversion and incubated at $37^{\circ} \mathrm{C}$ for exactly 30 minutes. Then reagent $\mathrm{D}$ (Ethyl Alcohol) was added to Blank and Test tubes. The reagent $\mathrm{C}$ was added to the Blank tube. The tubes were mixed by inversion, transferred to suitable cuvettes and recorded the absorbance at 243 nanometer $\left(\mathrm{A}_{243 \mathrm{~nm}}\right)$ in a spectrophotometer.

$$
\begin{aligned}
& \text { Units/ml enzyme }=\left(\mathrm{A}_{243 \mathrm{~nm}} \text { Test }-\mathrm{A}_{243 \mathrm{~nm}} \text { Blank }\right) \times \mathrm{V}_{1} \times \mathrm{df} / 30 \times 18 \\
& \mathrm{~V}_{2} \\
& \mathrm{~V} \text { = Volume (in milliliters) of the stopped reaction } \\
& 30=\text { Dilution factor } \\
& 18=\text { Mime (in minutes) of the assay as per the Unit Definition } \\
& \mathrm{V}_{2}=\text { Volume (in milliliter) of enzyme used. }
\end{aligned}
$$

Unit Definition: One unit will convert $1.0 \mu$ mole of cholesterol to 4-cholesten-3-one per minute at $\mathrm{pH} 5.0$ at $37^{\circ} \mathrm{C}$ [26].

In this work, ZnS nanoparticles are synthesized, characterized and used for the development cholesterol nanoprobe. The cholesterol nanoprobe is based on MWCNTs and $\mathrm{ZnS}$ nanoparticles with Cholesterol Oxidase (ChOx) immobilization in Nafian using Layer By Layer assembly technique. The electrochemical behavior of NafionZnS-MWCNTs-ChOx modified electrode and the kinetics of the immobilized enzyme ChOx are studied.

\section{Characterization of $\mathrm{ZnS}$ nanoparticles}

Nanoparticle characterization is necessary to establish understanding and control of nanoparticle synthesis and applications. Characterization is done by using a variety of different techniques. Common techniques are electron microscopy (TEM, SEM), atomic force microscopy (AFM), dynamic light scattering (DLS), x-ray photoelectron spectroscopy (XPS), powder X-ray diffraction (XRD), Fourier transform infrared spectroscopy (FTIR), matrix-assisted laser desorption/ionization time-of-flight mass spectrometry (MALDITOF), ultraviolet-visible spectroscopy, dual polarization interferometry and nuclear magnetic resonance (NMR). ZnS nanoparticles synthesized in this work are characterized by ultraviolet-visible spectroscopy, Fourier transform infrared spectroscopy and atomic force microscopy.

\section{UV absorbance spectrum of ZnS quantum dots}

The absorption spectra of PVP encapsulated ZnS nanoparticles are 
Citation: Navamani J, Palanisamy R, Gurusamy R, Ramasamy M, Arumugam S (2012) Development of Nanoprobe for the Determination of Blood Cholesterol. J Biosens Bioelectron 3:122. doi:10.4172/2155-6210.1000122

Page 4 of 8

shown in Figure 1. The onset of absorption is located at $290 \mathrm{~nm}(4.28$ $\mathrm{eV}$ ). The blue shift of absorption edge compared to bulk $\mathrm{ZnS}$ (onset is at $340 \mathrm{~nm}$ ) clearly explains the quantum confinement effect of $\mathrm{ZnS}$ nanoparticles. The absorption edges of the nanocrystallites are also sharp, indicating that the synthesized particles have relatively narrow size distributions.

\section{IR spectrum of $\mathrm{ZnS}$ nanoparticles}

Infra red spectroscopy exploits the fact that molecules have specific frequencies at which they rotate or vibrate corresponding to discrete energy levels (vibrational modes). These resonant frequencies are determined by shape of the molecular potential energy surfaces, the masses of atoms and by the associating vibronic coupling. The IR spectrum represents the molecular absorption and transmission, creating a molecular fingerprint of the sample. Like a fingerprint no two unique molecular structures produce the same infra red spectrum [27].

FTIR spectra of the PVP-capped ZnS are presented in the range $4000-500 \mathrm{~cm}^{-1}$ is shown in Figure 2. It is observed that absorption peaks in the range 1558 and $1418 \mathrm{~cm}^{-1}$ are ascribed to the $\mathrm{C}-\mathrm{H}$ bonding. This is due to the formation of co-ordinate bond between the nitrogen atom of the PVP and the $\mathrm{Zn}^{2+}$ ions. Therefore, the FTIR studies strongly support the formation of PVP-encapsulated $\mathrm{ZnS}$ nanoparticles.

\section{AFM image of $\mathrm{ZnS}$ nanoparticles}

The atomic force microscopy or scanning force microscopy is one of the important tools for imaging, measuring and manipulating

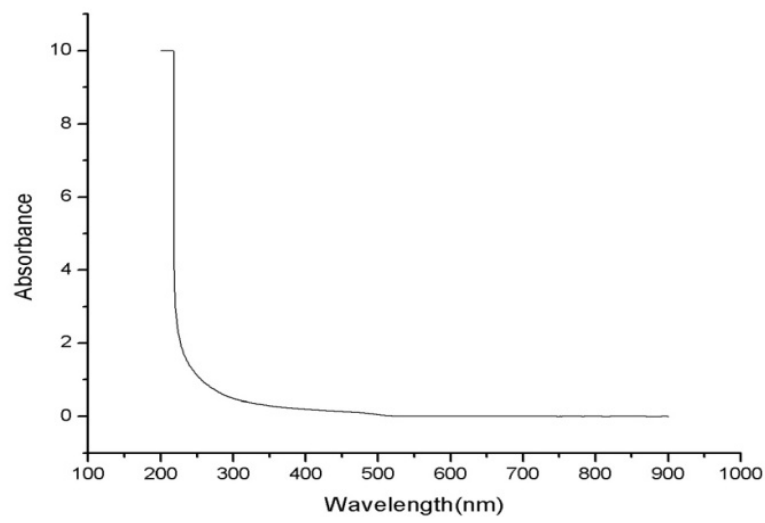

Figure 1: Absorption spectra of PVP-capped ZnS nanoparticles.

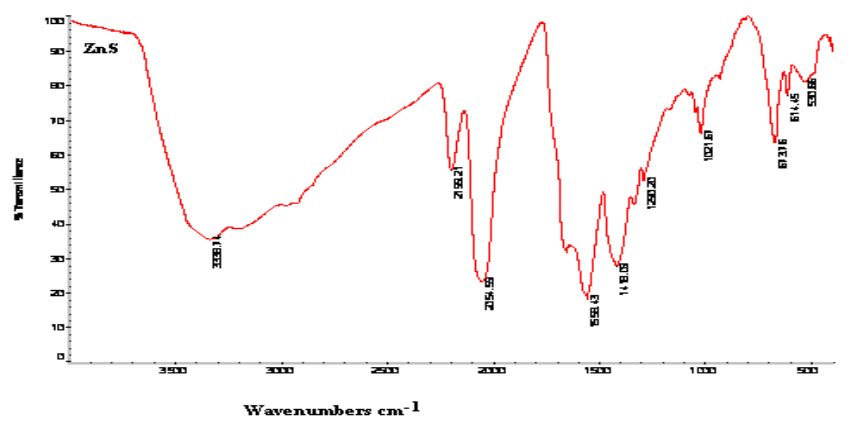

Figure 2: FTIR spectra of PVP-capped ZnS nanoparticles. materials at nanoscale (http://en.wikipedia.org/wiki/Atomic_force_ microscope).

Figure 3 shows an atomic force microscopy image for Zinc sulphide nanoparticles, with scan size of $2 \mu \mathrm{m} \times 2 \mu \mathrm{m}$. Height profile was taken across a quantum dot which shows the height of the quantum dot. The height and width were found to be approximately $8 \mathrm{~nm}$ and 86 $\mathrm{nm}$ respectively. An approximate histogram plot across the area was taken which shows increased distribution of particles with size ranging between 21-22 $\mathrm{nm}$.

\section{Characterization of functionalized MWCNTs}

The surface morphology of the sensing area of functionalized MWCNT was examined using scanning electron microscopy (SEM). The chemical property of the MWCNT was characterized by Fourier Transform Infrared Spectroscopy (FTIR).

\section{IR spectrum of functionalized-MWCNT}

The result on generation of surface functional groups obtained from FT-IR spectroscopy is shown in Figure 4. It is clear that several types of functional groups, particularly Carbonyl and hydroxyl groups have been generated on acid-oxidized Carbon nanotube surfaces as expected. Examination on surfaces of acid oxidized Carbon nanotubes was carried out using a Fourier transform infrared (FT-IR) spectrophotometer to ensure formation of desired surface functional

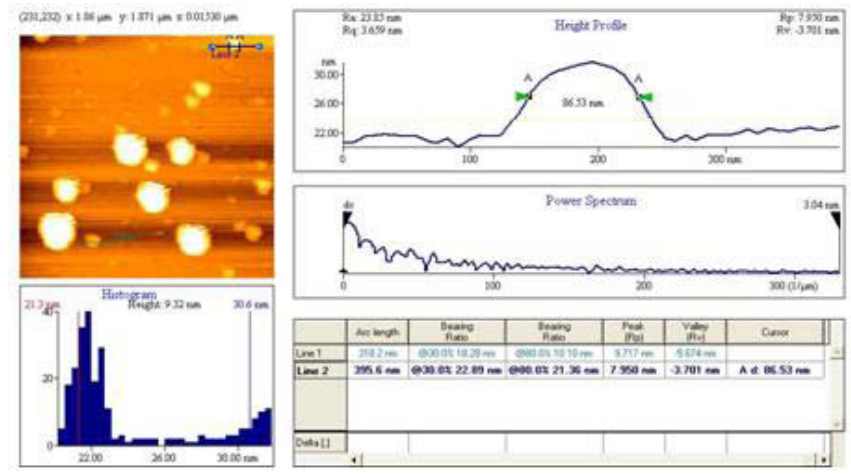

Figure 3: AFM image of PVP capped ZnS nanoparticles on mica, scan scale: $2 \mu \mathrm{m} \times 2 \mu \mathrm{m}$; height scale: $20 \mathrm{~nm}$.

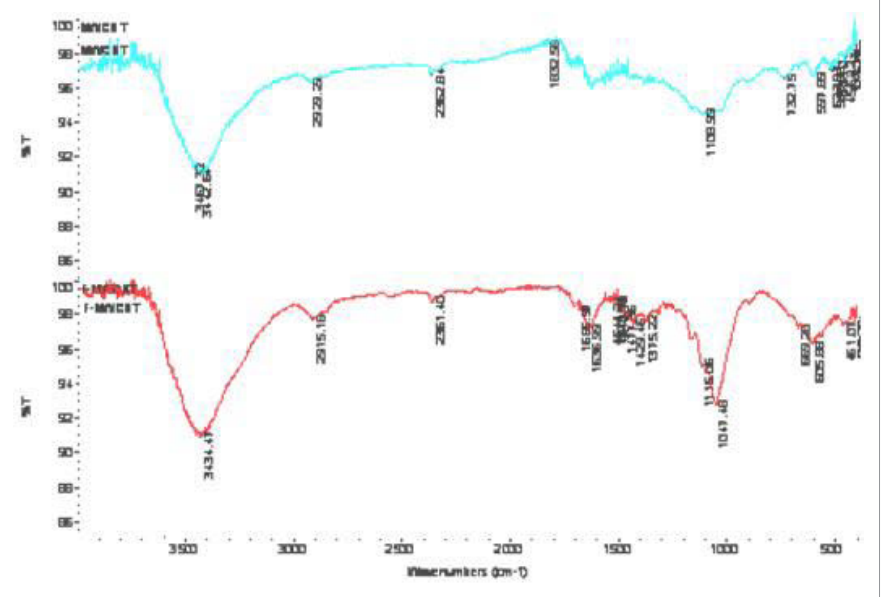

Figure 4: FT-IR spectrum of unfunctionalized and functionalized Multi walled Carbon nanotubes. 
groups (Figure 3 and 4). Also shows IR spectrum of unfunctionalized and functionalized MWCNTs, respectively. As seen from the spectrum of functionalized MWCNTs, the presence of bands at $1636 \mathrm{~cm}^{-1}$ and $3434 \mathrm{~cm}^{-1}$ confirmed the presence of Carbonyl and hydroxyl moieties of carboxylic acid group. This confirms that the Carbon nanotubes has been well functionalized with $-\mathrm{COOH}$, which was absent in unfunctionalized MWCNTs. The presence of $-\mathrm{COOH}$ groups on the surface of the MWNTs is advantageous for a better deposition of semiconducting nanoparticles on the surface of the MWNTs.

\section{SEM image of functionalized MWCNT}

The Figure 5 shows the SEM image of functionalized MWCNTs. After functionalization of MWCNTs some amorphous Carbons are in the picture. The length of the MWCNTs is approximately 2 microns.

\section{Electrochemical study of chemically modified electrode}

Electrochemical analysis involves the measurement of potential (potentiometry) or current response (voltametry). This study focused on current measurement (voltametry). Cyclic voltametry, Square wave voltametry, Linear sweep voltametry, Rotating disk electrode, Chronoamperometry, Galvanostatic charge discharge technique and electrocatalysis using voltametry are the various types of voltametry [28].

Cyclic voltametry is the most widely used electrochemical technique. In cyclic voltammetric experiment the potential of an electrode is cycled voltametry from a starting potential Ei to a final potential Ef and then back to Ei. The potential at which the peak current occurs is known as peak potential Ep. At this potential the redox species has been depleted at the electrode surface and diffusion is limited by the current. The magnitude of the Faradaic current Ipa (anodic peak current) or Ipc (cathodic peak current) is an indication of the rate at which electrons are being transferred between the redox species and the electrode [29].

The electrochemical behaviors of the Nafion-ZnS-MWCNTSChOx modified electrode fabricated by layer by layer assembly technique in this work were investigated by cyclic voltammetry.

\section{Electrochemical behavior of Nafion-ZnS-MWCNTS-ChOx modified electrode in $0.05 \mathrm{M}$ PBS (pH 7.0)}

In Figure 6, curve $\mathrm{d}$ is the cyclic voltammogram of a Nafion-ZnSMWCNTs-ChOx/GC electrode in 0.05 M PBS ( $\mathrm{pH}$ 6.0) at a scan rate of $50 \mathrm{mV} / \mathrm{s}$, while curve c, curve b and curve a are the cyclic voltammograms of a Nafion-ZnS-ChOx/GC electrode, Nafion-ChOx/GC electrode and a bare electrode, respectively. From the cyclic voltammogram, no redox peaks were observed at the bare electrode (curve a), Nafion-ChOx/GC electrode (curve b), Nafion-ZnS- ChOx/GC electrode (curve c) and Nafion-ZnS-MWCNTs-ChOx/GC electrode (curve d).

\section{Electrochemical behavior of Nafion-ZnS-MWCNTS-ChOx modified electrode in PBS solution with $30 \mathrm{mM}$ cholesterol}

In this work, the direct electrochemistry of ChOx on the NafionZnS-MWCNTs modified electrode was investigated. In Figure 7, curve $\mathrm{d}$ is the cyclic voltammogram of a Nafion-ZnS-MWCNTsChOx/GC electrode in $0.05 \mathrm{M}$ PBS ( $\mathrm{pH}$ 6.0) with $30 \mathrm{mM}$ cholesterol at a scan rate of $50 \mathrm{mV} / \mathrm{s}$, while curve $\mathrm{c}$, curve $\mathrm{b}$ and curve a are the cyclic voltammograms of a Nafion-ZnS-ChOx/GC electrode, Nafion$\mathrm{ChOx} / \mathrm{GC}$ electrode and a bare electrode, respectively. From the cyclic voltammogram, no redox peaks were observed at the bare electrode (curve a) and Nafion-ChOx/GC electrode (curve b), and the redox

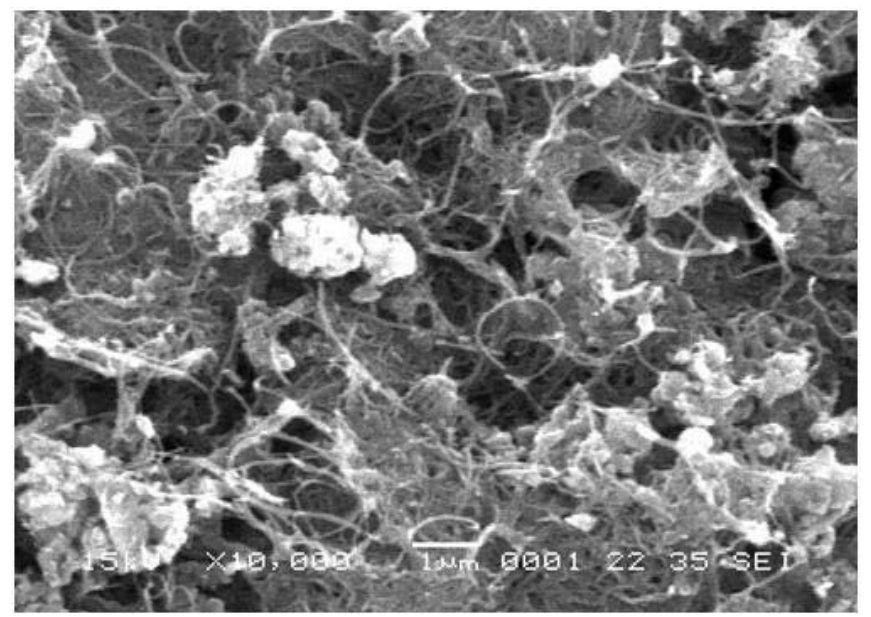

Figure 5: SEM image of functionalized multi wall Carbon nanotubes.

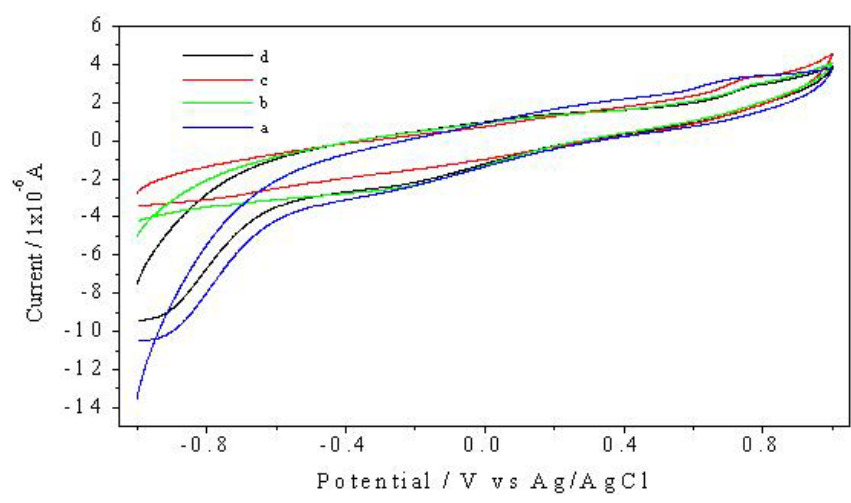

Figure 6: Cyclic voltammograms of (a) bare electrode, (b) ChOx-Nafion/GC, (c) ZnS-ChOx/GC and (d) ZnS MWCNTs-ChOx-Nafion/GCin 0.05M PBS (pH 7.0).

peaks at the Nafion-ZnS-ChOx/GC electrode (curve c) were very small. In contrast, there was a pair of well-defined and quasi-reversible redox peaks at the Nafion-ZnS-MWCNTs-ChOx/GC electrode (curve d). The formal potential $E^{\circ}$, the average of the anodic and cathodic peak potentials, was estimated to be $-0.461 \mathrm{~V}$.

The cathodic and anodic peak currents were of similar magnitude, with a ratio about unity. The anodic peak potential and the cathodic peak potential of curve $d$ in Figure 4 and 7 were respectively $-0.234 \mathrm{~V}$ and $-0.688 \mathrm{~V}$ with a small peak potential separation $(\Delta \mathrm{Ep}=454 \mathrm{mV})$, revealing a fast electron transfer process.

All of these results indicate that the direct electron transfer of $\mathrm{ChOx}$ was achieved through the incorporation of ChOx into the Nafion-ZnSMWCNTs film. ZnS QDs and MWCNTs played an important role in facilitating the electron transfer between the proteins and the electrode surface, which might be due to a higher charge detaching efficiency of quantum dots resulting from its quantum size effect and the favorable orientation of ChOx molecules in the composite film, etc.

\section{Electrochemical behavior of Nafion-ZnS-MWCNTS-ChOx modified electrode in $30 \mathrm{mM}$ cholesterol at various scan rates}

The Figure 3 and 8 is the cyclic voltammograms of the Nafion-ZnSMWCNTs-ChOx/GC electrode at various scan rates. The redox peak currents were scanning rate-dependent. With the scan rate increasing, 
Citation: Navamani J, Palanisamy R, Gurusamy R, Ramasamy M, Arumugam S (2012) Development of Nanoprobe for the Determination of Blood Cholesterol. J Biosens Bioelectron 3:122. doi:10.4172/2155-6210.1000122

Page 6 of 8

the cathodic and anodic peak currents increased simultaneously. A linear relationship between them with scan rate from 0.05 to $0.2 \mathrm{~V} / \mathrm{s}$ revealed that the electron transfer between $\mathrm{ChOx}$ and GC electrode could be easily performed at the Nafion-ZnS-MWCNTs-ChOx composite film.

\section{Study of immobilised ChOx kinetics}

Enzyme kinetics is the study of the chemical reactions that are catalyzed by enzymes. In enzyme kinetics, the reaction rate is measured and the effects of varying the conditions of the reaction studied. Studying the enzyme's kinetics in this way can reveal the catalytic mechanism of the enzyme.

\section{Effect of cholesterol concentration on the activity of immobilised $\mathrm{ChOx}$}

Michaelis-Menten kinetics of an enzyme describes the rate of enzymatic reactions, by relating reaction rate $\mathrm{v}$ to the concentration of a substrate [S]. Its formula is given by

$$
v=\frac{V_{\max }[S]}{K_{m}+[S]}[30]
$$

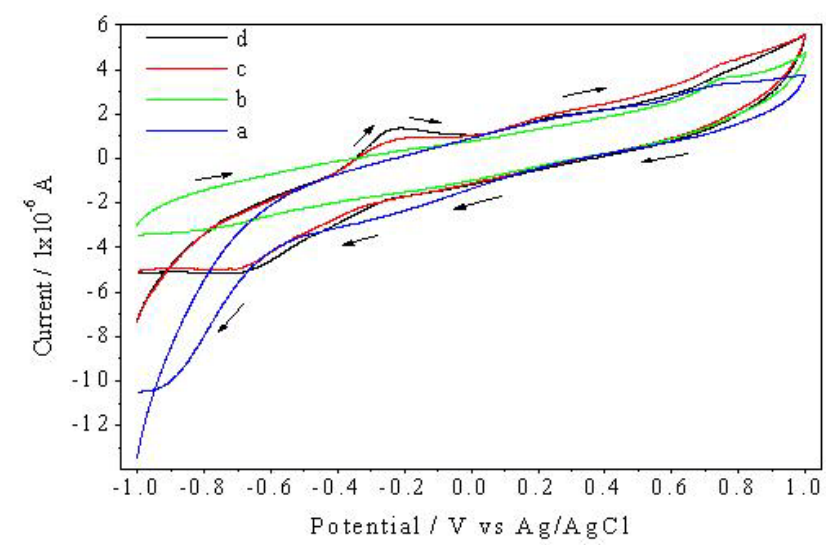

Figure 7: Cyclic voltammograms of (a) bare electrode, (b) Nafion-ChOx/GC, (c) Nafion-ZnS-ChOx/GC and (d) Nafion-ZnS-MWCNTs-ChOx/GC in 0.05M PBS (pH 6.0) with $30 \mathrm{mM}$ Cholesterol.

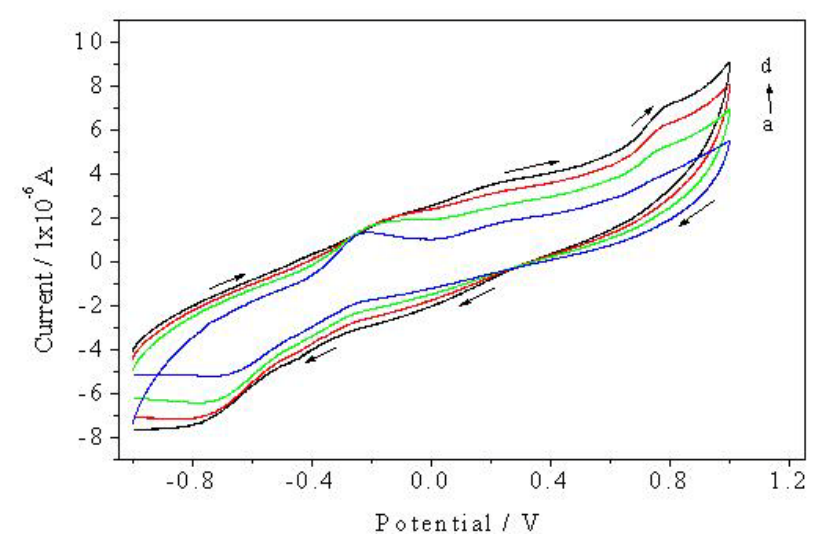

Figure 8: Cyclic voltammograms of the Nafion-ZnS-MWCNTs-ChOx/GC electrode in $0.05 \mathrm{M}$ PBS $(\mathrm{pH} \mathrm{6.0)}$ with $30 \mathrm{mM}$ Cholesterol at various scan rates. Scan rate (from a-d) is $50,100,150,200 \mathrm{mVs}^{-1}$, respectively.
The Michaelis-Menten constant $K_{m}$ is the substrate concentration at which the reaction rate is at half-maximum, and is a measure of the substrate's affinity for the enzyme. A small $K_{m}$ indicates high affinity, meaning that the rate will approach $V_{\max }$ more quickly.

The enzyme response to cholesterol concentration has been carried out. Figure 9 shows the enzyme activity to different concentrations of cholesterol. There are ten different concentrations of cholesterol standard solution $(50,100,150,200,250,300,350,400,450$ and $500 \mathrm{mg} / \mathrm{dl}$ ) have been applied. The enzyme activity was increasing according to the rise of cholesterol concentration. The MichaelisMenten and Lineweaver-Burke plots were drawn to study the kinetics of immobilized Cholesterol Oxidase.

The immobilized ChOx exhibits detection range of $10-450 \mathrm{mg} / \mathrm{dl}$, and good linearity is obtained in $50-450 \mathrm{mg} / \mathrm{dl}(1.3-11.6 \mathrm{mM})$ range with linear regression coefficient ' $\mathrm{R} 2$ ' as 0.997 .

The Michaelis-Menten constant $\left(K_{m}\right)$ is a parametric statistic for describing the affinity between the enzyme and substrate in enzymatic reactions. In order to examine the activity of enzymes in biosensors, the apparent Michaelis-Menten constant $\left(K_{m}\right)$ of ChOx was determined.

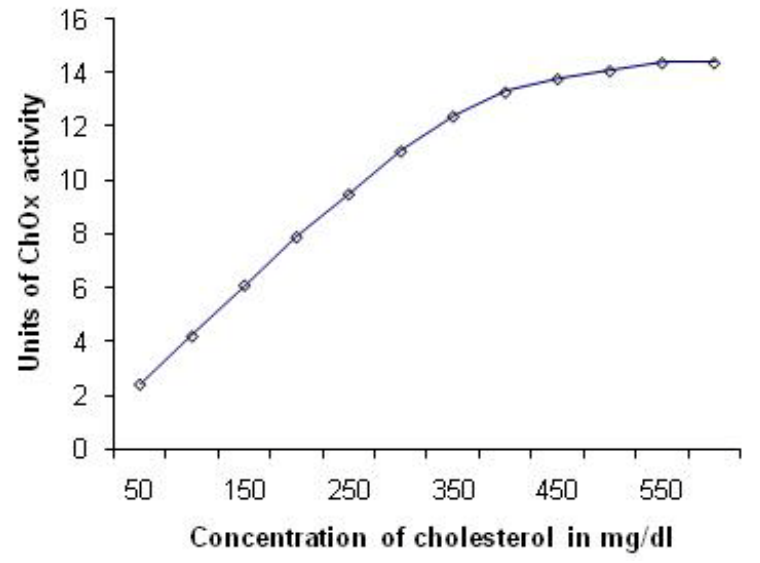

Figure 9: The activity of immobilized $\mathrm{ChOx}$ in different concentrations of cholesterol (Michaelis-Menten plot) in $0.05 \mathrm{M}$ phosphate buffer $\mathrm{pH} 7.0$ at $37^{\circ} \mathrm{C}$.

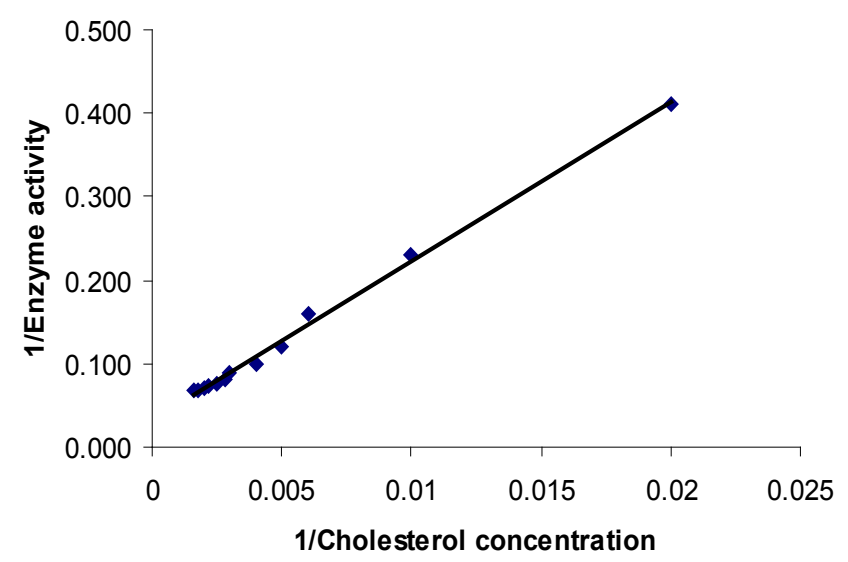

Figure 10: Lineweaver-Burk plot for immobilized Cholesterol Oxidase. 
A Lineweaver-Burk double reciprocal plot based on the experimental data is shown in Figure 3 and 10. This is drawn by taking the reciprocal of both sides of the Michaelis-Menten equation. This is a linear form of the Michaelis-Menten equation and produces a straight line with the equation $y=m x+c$ with a $y$-intercept equivalent to $1 / V_{\max }$ and an $\mathrm{x}$-intercept of the graph representing $-1 / K_{M}[31]$.

$$
\frac{1}{v}=\frac{K_{M}}{V_{\max }[S]}+\frac{1}{V_{\max }}
$$

The value of $K_{m}(0.84 \mathrm{mM})$ is calculated from the intercept and slope of the Lineweaver-Burk plot (Figure 10). The low $K_{m}$ value 0.84 $\mathrm{mM}$ indicates high affinity of immobilized ChOx to cholesterol. The smaller $K_{m}$ value also indicates that the diffusion of substrate and product into and out of the membrane is easy in the present NafionZnS-MWCNTs-ChOx/GC electrode composite matrix.

\section{Effect of $\mathrm{pH}$ on immobilized ChOx activity}

The $\mathrm{pH}$ of the solutions containing substrates can affect the overall enzymatic activity since, like all natural proteins, enzymes have a native tertiary structure that is sensitive to $\mathrm{pH}$; denaturation of enzymes can occur at extreme pHs. It is well known that the enzyme activity is highly $\mathrm{pH}$ dependent and the optimum $\mathrm{pH}$ for an enzymatic assay must be determined empirically. It is best to choose a plateau region for enzyme assay so that the $\mathrm{pH}$ should not have any effect on enzyme activity. Stoytcheva [32] has studied the activity of the immobilized acetyl cholinesterase between $\mathrm{pH} 2$ and $\mathrm{pH}$ 9. She has reported that the activity was decreased of approximately $70 \%$ at $\mathrm{pH} 2$ compared to of that at $\mathrm{pH} 7$.

The effect of different $\mathrm{pH}$ on the activity of immobilized Cholesterol Oxidase enzyme was examined and shown in Figure 11. The optimum enzyme activity was obtained at $\mathrm{pH}$ 7.0. The optimum $\mathrm{pH}$ value for the enzyme activity in homogeneous solution has been reported to be 7.0 [33]. Therefore, enzyme immobilization procedure did not cause a change in optimum $\mathrm{pH}$ of enzyme activity.

\section{Effect of temperature on immobilized ChOx activity}

The rate of an enzyme-catalyzed reaction increases as the temperature is raised. A ten degree Centigrade rise in temperature will increase the activity of most enzymes by 50 to $100 \%$. Variations in reaction temperature as small as 1 or 2 degrees may introduce changes of 10 to $20 \%$ in the results. In the case of enzymatic reactions, the reaction rate increases with temperature to a maximum level, then abruptly declines with further increase of temperature. Most enzymes rapidly become denatured at temperatures above $40^{\circ} \mathrm{C}$ [34].

Temperature exerts a marked influence on the Cholesterol Oxidase activity. The effect of temperature on the enzyme activity was examined in the range of $10-60^{\circ} \mathrm{C}$. The optimum temperature was found in the range of $35^{\circ} \mathrm{C}$ (Figure 12).

\section{Conclusion}

In this study, a novel nanoprobe (Nafion-ZnS-MWCNTsChOx/GC) was developed for cholesterol determination in blood by using LBL assembly technique. This study has shown that the ZnS nanoparticles and MWCNTs act as an effective mediator between the enzyme Cholesterol Oxidase and a glassy carbon electrode. Nafion was incorporated into a glassy carbon electrode upon which Cholesterol Oxidase has been immobilized. It provides all the features required for the analysis of cholesterol in clinical samples. Its performance rests on a number of features: the rapid rate of electron transfer between reduced

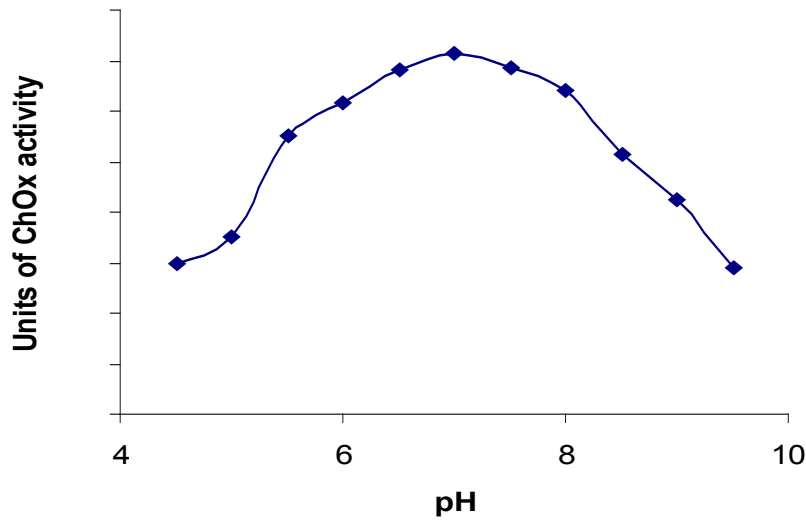

Figure 11: The activity of immobilized $\mathrm{ChOx}$ in different $\mathrm{pH}$ at $37^{\circ} \mathrm{C}$.

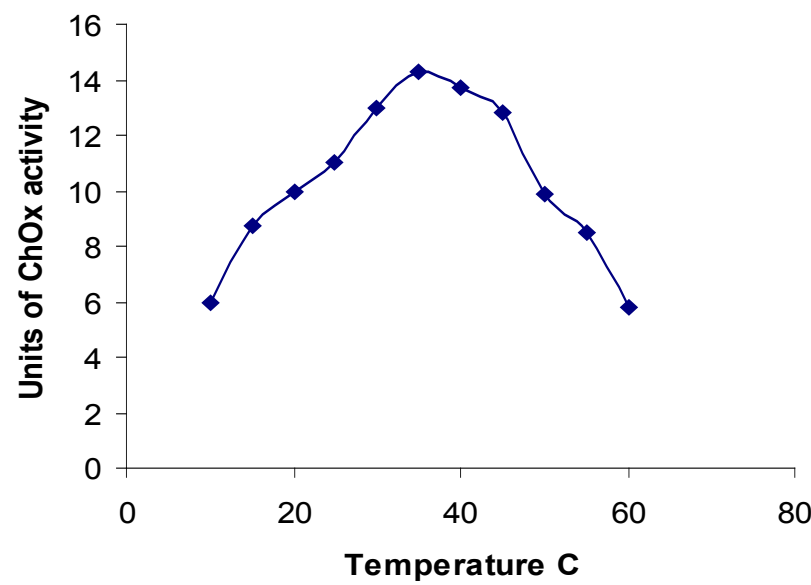

Figure 12: The activity of immobilized $\mathrm{ChOx}$ at different temperatures in $\mathrm{pH}$ 7.0.

enzyme and the $\mathrm{ZnS}$ nanoparticles; the good electrochemical properties of MWCNTs and Nafion resulting in the effective confinement of the mediator to the electrode surface.

The optimum $\mathrm{pH}$ and temperature of the sensor was found to be 7.0 and $35^{\circ} \mathrm{C}$ respectively. The developed sensor was calibrated with $50-600 \mathrm{mg} / \mathrm{dl}$ of cholesterol and found to have linearity of 50 $450 \mathrm{mg} / \mathrm{dl}$. The calibration curve was drawn with initial velocity of the enzyme catalysed reaction $V i$ (One unit will convert $1.0 \mu$ mole of cholesterol to 4 -cholesten-3-one per minute at $\mathrm{pH} 5.0$ at $37^{\circ} \mathrm{C}$ ) vs. different concentrations of standard cholesterol solution $(\mathrm{mg} / \mathrm{dl})$. The low $K_{m}$ value $0.84 \mathrm{mM}$ indicates high affinity of immobilized ChOx to cholesterol. The smaller $K_{m}$ value also indicates that the diffusion of substrate and product into and out of the membrane is easy in the present Nafion-ZnS-MWCNTs-ChOx/GC electrode composite matrix.

\section{References}

1. Clark LC Jr, Lyons C (1962) Electrode systems for continuous monitoring in cardiovascular surgery. Ann N Y Acad Sci 102: 29-45.

2. Frackowiak E, Beguin F (2001) Carbon materials for the electrochemical storage of energy in capacitors. Carbon 39: 937-950.

3. Gurunathan K, Murugan AV, Marimuthu R, Mulik UP, Amalerkar DP (1999) Electrochemically synthesised conducting polymeric materials for applications towards technology in electronics, optoelectronics and energy storage devices. Mater Chem Phys 61: 173-191. 
Citation: Navamani J, Palanisamy R, Gurusamy R, Ramasamy M, Arumugam S (2012) Development of Nanoprobe for the Determination of Blood Cholesterol. J Biosens Bioelectron 3:122. doi:10.4172/2155-6210.1000122

4. Kim IH, Kim KB (2001) Ruthenium oxide thin film electrodes for supercapacitors. Electrochem Solid-State Lett 4: A62-A64.

5. Singh S, Solanki PR, Pandey MK, Malhotra BD (2006) Cholesterol biosensor based on cholesterol esterase, cholesterol oxidase and peroxidase immobilized on conducting polyaniline films. Sensor Actuat B-Chem 115: 534-541.

6. Salimi A, Hallaj R (2005) Catalytic oxidation of thiols at preheated glassy carbon electrode modified with abrasive immobilization of multiwall carbon nanotubes: applications to amperometric detection of thiocytosine, I-cysteine and glutathione. Talanta 66: 967-975.

7. lijima S (1991) Helical microtubules of graphitic Carbon. Nature 354: 56-58.

8. Zhong J, Song L, Meng J, Gao B, Chu WS, et al. (2009) Bio-nano interaction of proteins adsorbed on single-walled carbon nanotubes. Carbon 47: 967-973.

9. Banks CE, Compton RG (2004) Ultrasound: promoting electroanalysis in difficult real world media. Analyst 129: 678-683.

10. Britto PJ, Santhanam KSV, Rubio A, Alonso JA, Ajayan PM (1999) Improved Charge Transfer at Carbon Nanotube Electrodes. Adv Mater 11: 154-157.

11. Wang J, Musameh M (2004) Carbon nanotube screen-printed electrochemica sensors. Analyst 129: 1-2.

12. Kerman K, Saito M, Yamamura S, Takamura Y, Tamiya E (2008) Nanomaterialbased electrochemical biosensors for medical applications. TRAC-Trend Anal Chem 27: 585-592

13. Jaiswal JK, Mattoussi H, Mauro JM, Simon SM (2003) Long-term multiple color imaging of live cells using quantum dot bioconjugates. Nat Biotechnol 21: 4751.

14. Solanki PR, Kaushik A, Ansari AA, Sumana G, Malhotra BD (2008) Zinc oxidechitosan nanobiocomposite for urea sensor. Appl Phys Lett 93: 163903163905.

15. Chopra N, Gavalas VG, Bachas LG, Hinds BJ, Bachas LG (2007) Functional one-dimensional nanomaterials: applications in nanoscale biosensors. Anal Lett 40: 2067-2096.

16. Wang JX, Sun XW, Wei A, Lei Y, Cai XP, et al. (2006) Zinc oxide nanocomb biosensor for glucose detection. Appl Phys Lett 88: 233106-233108.

17. Bidan G, Billon M, Galasso K, Livache T, Mathis G, et al. (2000) Electropolymerization as a versatile route for immobilizing biological species onto surfaces. Application to DNA biochips. Appl Biochem Biotechnol 89: 183193.

18. Lange U, Roznyatovskaya NV, Mirsky VM (2008) Conducting polymers in chemical sensors and arrays. Anal Chim Acta 614: 1-26.

19. Palaniappan S, John A (2008) Polyaniline materials by emulsion polymerization pathway. Prog Polym Sci 33: 732-758.
20. Bowman TS, Sesso HD, Ma J, Kurth T, Kase CS, et al. (2003) Cholesterol and the risk of ischemic stroke. Stroke 34: 2930-2934.

21. Vidal JC, Garcia-Ruiz E, Castillo JR (2003) Recent Advances in Electropolymerized Conducting Polymers in Amperometric Biosensors. Microchim Acta 143: 93-111.

22. Savadogo O (1998) Emerging membranes for electrochemical systems: (I) solid polymer electrolyte membranes for fuel cell systems. J New Mater Electrochem Syst1: 47-66.

23. Ghosh G, Naskar MK, Patra A, Chatterjee M (2006) Synthesis and characterization of PVP-encapsulated ZnS nanoparticles. Opt Mater 28: 10471053.

24. Huang Y, Zhang W, Xiao H, Li G (2005) An electrochemical investigation of glucose oxidase at a CdS nanoparticles modified electrode. Biosens Bioelectron 21: 817-821.

25. Zhang J, Feng M, Tachikawa $H$ (2007) Layer-by-layer fabrication and direct electrochemistry of glucose oxidase on single wall carbon nanotubes. Biosens Bioelectron 22: 3036-3041.

26. Richmond W (1973) Preparation and properties of a cholesterol oxidase from Nocardia sp. and its application to the enzymatic assay of total cholesterol in serum. Clin Chem 19: 1350-1356.

27. Copper CL, Collins GE (2004) Separation of thiol and cyanide hydrolysis products of chemical warfare agents by capillary electrophoresis. Electrophoresis 25: 897-902.

28. Christensen PA, Hamnett A (1994) Techniques and Mechanisms in Electrochemistry- The New Chemistry. Cambridge University Press, UK.

29. Christensen P, Hamnett A (1991) In situ spectroscopic investigations of the growth, electrochemical cycling and overoxidation of polypyrrole in aqueous solution. Electrochim Acta 36: 1263-1286.

30. Lehninger AL, Nelson DL, Cox MM (2005) Lehninger principles of biochemistry. W.H. Freeman, New York, USA

31. Tseng SJ, Hsu JP (1990) A comparison of the parameter estimating procedures for the Michaelis-Menten model. J Theor Biol 145: 457-464.

32. Stoytcheva M (2002) Electrochemical evaluation of the kinetic parameters of heterogeneous enzyme reaction in presence of metal ions. Electroanalysis 14 923-927.

33. Umar A, Rahman MM, Al-Hajry A, Hahn YB (2009) Highly-sensitive cholestero biosensor based on well-crystallized flower-shaped $\mathrm{ZnO}$ nanostructures. Talanta 78: 284-289

34. Holum J (1968) Elements of General and Biological Chemistry. ( $2^{\text {nd }}$ edn), Wiley, New York, USA. 